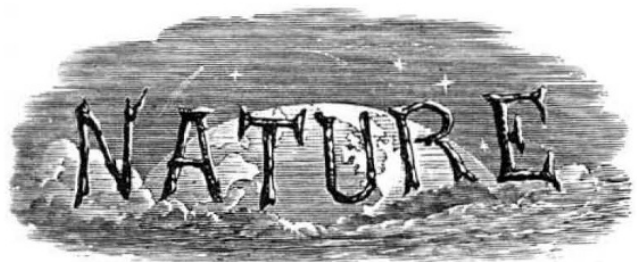

SATURDAY, JANUARY I7, 1925.

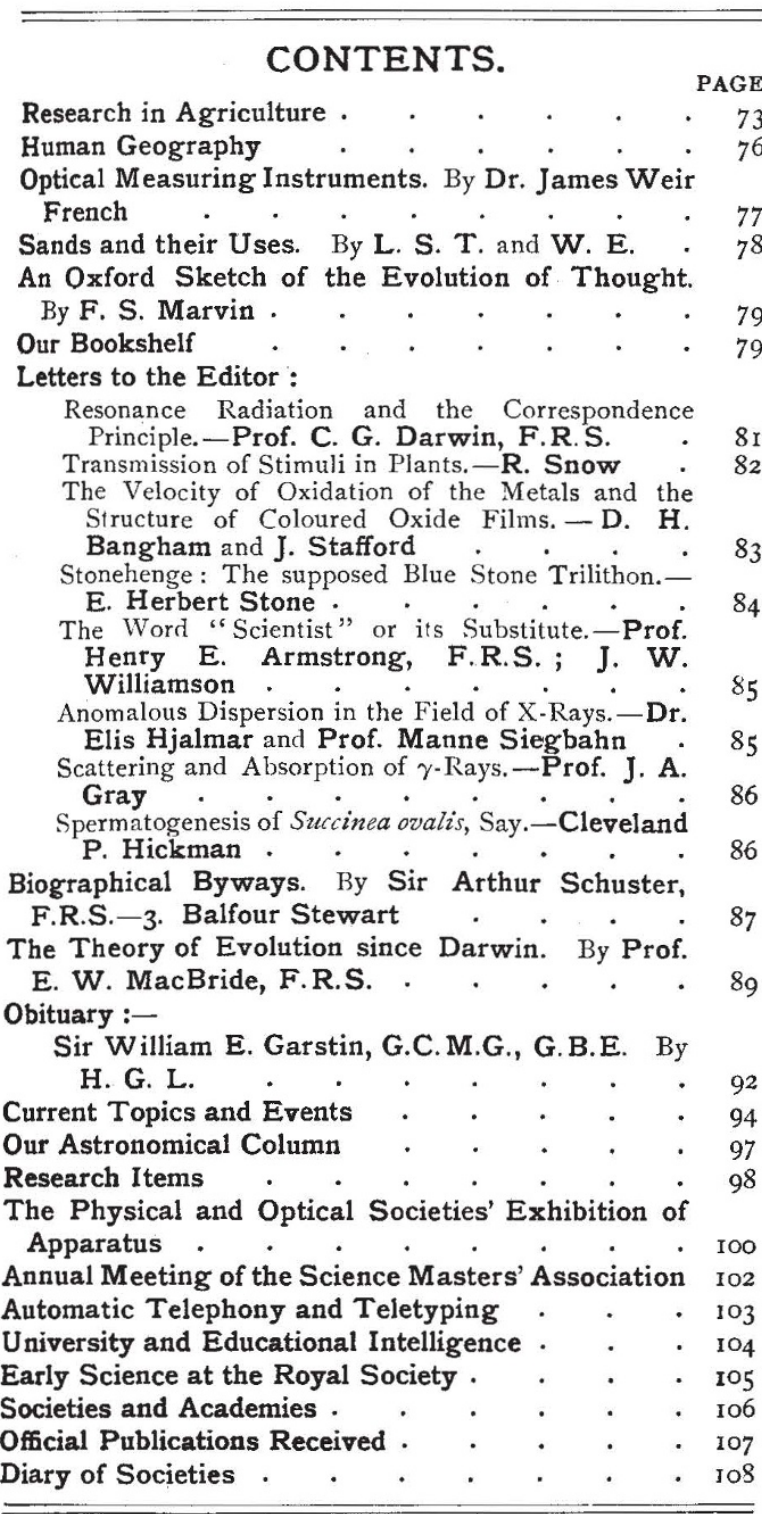

Editorial and Publishing Offices:

MACMILLAN \& CO., LTD.,

ST. MARTIN'S STREET, LONDON, W.C. 2.

Editorial communications should be addressed to the Editor. Advertisements and business letters to the Publishers.

Telephone Number: GERRARD 8830.

Telegraphic Address: PHUSIS, WESTRAND, LONDON.

\section{Research in Agriculture.}

LTHOUGH the Development Commissioners are A not themselves directly responsible for agricultural education and research during the last fourteen years, the manner in which the funds subject to the jurisdiction of the Commissioners have been portioned out has exercised a dominating influence on both the quality and quantity of scientific information that has been recently acquired, and on the nature of the organisation by which it has been sought to render this information of immediate assistance to the farmer. If the fourteenth Report of the Development Commissioners (H.M.S.O., 4s. net) is read in conjunction with the first and later reports, it will be noted that the Commissioners have favoured and adhered to a more or less definite policy from the outset. They realised that one of the primary needs was to assist in the training of men competent to conduct research, and then to accelerate research on the fundamental problems underlying agricultural practice. The body of scientific men at present employed in connexion with agricultural science is to-day vastly greater than it was fourteen years ago, and it is probably not too much to say that the average training which these men have received, and also the attainments and qualifications of the average man, are decidedly better.

It has been the policy of the Commissioners to add to the volume of research, chiefly by assisting in the initiation and maintenance of Research Institutes and Experimental Stations, and there are now about twenty such stations in Great Britain dealing with fundamental problems. It is interesting in passing to note that the necessity of having more than one institution to deal with certain problems which have specially local application has now been realised and acted upon ; thus England, Scotland, and Wales has each a Plant Breeding Station aided by grants from the Development Fund, while the needs of horticulture, for example, are recognised at more than one institution.

The Report before us affords ample evidence of the quality and quantity of the research in progress at these institutions. It is beyond the scope of the present article to attempt to review this work. It is necessary, however, to lay emphasis on its fundamental character, the vast majority of the scientific papers for which the staffs of the institutions have been responsible dealing with difficult problems approached in an exhaustive manner and by purely scientific methods. There can, in short, be not the least doubt that the policy of the Development Commissioners has been successful to a marked degree in two highly important directions. To-day we have, comparatively speaking, a large, and in the main a well-qualified, body of agricultural scientific workers, and a vast mass of accurate scientific

NO. 288 I, VOL. I I 5$]$ 
data of great potential value to the farmer and to the nation. No reasonable criticism can be levelled against the Commissioners for the manner in which the funds have been apportioned in relation to solving the problems of the various branches of the industry, although to some it may appear that horticulture has been treated more generously than would at first sight seem to be justified by its position in Great Britain. It has, however, to be realised that horticulture is an intensive industry employing a considerable amount of labour, and thus any extension of fruit culture or market gardening must immediately and inevitably react in a favourable manner on the rural population.

It is obvious that science cannot of itself redeem an industry which is in the main under-capitalised and very largely unprofitable. It should, however, be equally obvious that if the conference of land-owners, farmers, and land-workers recently convened by the present Government can in fact agree on a sound agricultural policy at once far-sighted and acceptable to the nation as a whole, the ultimate success of that policy will be largely determined by the extent to which science is brought to the direct aid of the farmer. It is, therefore, legitimate to examine the organisation which exists to-day for the explicit purpose of bringing science to the direct aid of the farmer, and to do so in the light of what are considered to be the chief necessities of British agriculture, if this industry is to be regarded as of national importance as well merely as of something which concerns the well-being of what is no inconsiderable proportion of our population.

The Commissioners have, of course, realised the necessity of a connecting link between the Research Institutions and the county organisers who are primarily responsible for advising the farmer as to scientific practices. Advisory officers are now attached to fourteen institutions; the majority of these are, however, advisory chemists and pathologists whose chief preoccupation in most cases is to undertake research on laboratory lines into problems of local importance, and in the main they have not the facilities to investigate farm practices as such. It is therefore satisfactory to note that Advisors in Economics are now being appointed at some of the institutions, and the work already done, notably at the University of Leeds, would seem to indicate that, particularly when the officers devote their attention to the economics of local practices, they are able to afford signal service to the farmers within their areas. Recent results obtained at the Research Institutes in the realm of animal nutrition have been followed up at college farms by accurate feeding trials, so that it is now possible for organisers who have had the opportunity of gaining personal experience to give authoritative advice to individual farmers, which has in innumerable cases revolutionised the system of feeding adopted. In this connexion the pioneer work of Mr. Boutflour in Wiltshire affords one of the best recent examples of the way in which science has been brought to the direct and very substantial aid of the farmer, and has incidentally caused increased production, in this case in terms of gallons of milk. It is perhaps open to doubt, however, whether science has been brought sufficiently to bear on some of the wider and more national aspects of agriculture in Great Britain.

Mr. Edward Wood, the Minister of Agriculture, in recent speeches and referring to the conference of those concerned in the industry he has convened, has emphasised the need of adding to the area under cultivation in Great Britain, not necessarily by merely thinking in terms of wheat alone, and he has directed attention to the paramount need of making our more derelict lands fertile and this whether particular areas are left in grass or brought under the plough. Mr. Wood has also directed attention to the serious disadvantage under which the farmer labours in regard to bringing his farm into a higher state of fertility as the result of paucity of readily available working capital.

Broadly stated, then, one of the first necessities, if we are to have a healthy agriculture, is a campaign of land improvement in the widest sense, and from the facts of the case, no matter whether credit facilities are to be afforded to the farmer on a large scale or not, the improvements must be effected on an economic basis.

Here, then, is a concrete, yet highly composite problem, a problem towards the solution of which agricultural science has admittedly accumulated a vast array of data. But the items contributing to such data are largely unrelated and cannot at present be said to constitute a definite and trustworthy practical doctrine.

The allied questions of improving poor land and generally enhancing the fertility of farm lands in Great Britain as a whole are not subjects upon which the organiser can easily persuade the farmer himself to experiment. The problems involved entail, first, diffcult economic considerations, and secondly, the elucidation of practical difficulties connected with the type of rotation and systems of cropping most suitable, methods of tillage, processes of manuring, relation of grass to arable, and the choice of the correct varieties and strains of crops. The general problem is not, moreover, one that is likely to be adequately dealt with at an institutional farm; for one thing, these farms are frequently of a higher grade than the average of the district which they represent, and for another, it is usually the policy to run such farms in conformity with the generally accepted canons of good husbandry.

Indirectly, valuable work has been accomplished in

$$
\text { No. } 288 \text { I, VOL. I I } 5]
$$


the direction of surveying the field by the various soil and other surveys that have been undertaken. Hitherto, however, no large sum of money has been set aside for this important work, which has been conducted in a somewhat haphazard manner and in many cases without critical regard to economic considerations. In any event, it is work that needs to be conducted on a wellthought-out and uniform plan, under the general supervision of a strong co-ordinating authority. The need of a complete agricultural survey showing both actualities and potentialities was rendered abundantly manifest during the War, while if a real endeavour is to be made to stabilise the industry and add to the productive capacity of farm lands in Great Britain, the nonexistence of such a record will again be acutely felt.

In so far as growing the correct varieties of the chief crops is concerned, it is satisfactory to learn that a grant has been made to the National Institute of Agricultural Botany to enable that organisation to conduct subsidiary trials at carefully selected sub-stations. It is, however, on the poorer and more improvable types of land that variety trials are most needed, while in many cases the type of varieties necessarily handled by the National Institute are not likely to be those best suited to land of the lower productive classes. Trials of a somewhat different nature should also be initiated ; the aim in the first place would be to discover the degree of productivity of every characteristic district, by setting up a series of properly replicated plots of the same standard variety-of a crop of wide-spread distribution such as oats-on as many farms as possible.

This is a procedure that should constitute an important feature of any general scheme of agricultural survey that may be set on foot, for without some really trustworthy quantitative and easily comparable crop data of this sort it is difficult to see how the results of surveys based on soil and other environmental factors can be interpreted to proper economic advantage. In the second place, it is exceedingly important to know the range of applicability of new and improved varieties, and it is just as important that the greatest possible number of farmers should be given the opportunity of forming their own opinion of such varieties.

With a view to these ends quantitative data are not necessary, or at all events not necessary in the first instance. A strip of, say, Yeoman wheat should be sown on a few fields in every parish in the country in which wheat, in no matter how small quantity, is grown. The same would apply to, say, Black Bell III. and Victory or Crown oats, while in particular districts it would be easy for the appropriate advisory centres to make proper suggestions as to varieties demanding extensive trials by this means. A similar simple method would make it possible rapidly and accurately to define the areas capable of successful lucerne cultivation, to establish the relative merits of widely different strains of such a fundamentally important crop as red clover for widely different habitats. All of these are problems of first-rate importance in relation to profitable land improvement. More urgent than trials of the character indicated above is the necessity for conducting experiments in the realm of systems of cropping, and the relation of temporary to permanent grass, which would entail equally farflung but more elaborate and long-continued field trials.

It is true that financial support has been given to further the idea of arable dairy-farming, and that the utilisation of barren sandy land has been under tentative investigation, but these are isolated aspects of the broad question of enhanced crop production and land improvement. They are not so much the province of agricultural chemistry or of agricultural botany as understood in Great Britain, but rather of field husbandry or agronomy as understood and investigated in the United States of America, for example.

Notwithstanding the work that is in progress in many important directions influencing land improvement, it is probably not too much to say that the problems of field husbandry will not be solved until an ad hoc organisation is set up to deal with the matter in a 'manner analogous to that in which the Research Institutions deal with the fundamental problems of plant breeding and animal nutrition, for example, or the way in which the advisers in agricultural chemistry deal with their local problems. It is doubtful, however, if a single Research Institute of field husbandry would adequately meet the case-numerous substations would certainly be a necessity. It is, however, the principle that field husbandry is not at present a matter of demonstration, but is essentially a matter demanding field investigation of a most rigorous and accurate character, conducted without bias and in a true spirit of research, that must be realised. Two things are essential, namely, a co-ordinating authority and the appointment of men in the counties backed with facilities for conducting field investigations on carefully selected areas. A useful beginning could undoubtedly be made if advisers in field husbandry were appointed at institutions serving backward and infertile districts, while co-ordination could be assured by the appointment of an officer at the Ministry of Agriculture charged with the supervision of the work as a whole. It is probable that in some cases suitable land could be taken over for experimental purposes from the not inconsiderable areas now under the control of the Forestry Commission, while it is more than likely that land-owners and farmers would be found in very appreciable numbers who would be willing to assist in such an important undertaking. 